ranged from 50 to 82 years, with a mean of 63.9. Twenty (mean age at operation, 62.6 years) of them were administered EHDP, and the rest 20 (mean age at operation, 65.1 years) were not administered the agent. The administration was initiated within 2 weeks postoperatively at a daily dose of $600-1000 \mathrm{mg}$, and continued for 12 weeks. The patients were clinically evaluated 4, $8,12,24$, and 96 weeks and 8 years after the start of administration. The Finermann's classification was used for radiological evaluation of ectopic bone formation.

Results The incidences of ectopic bone formation 24, 96 weeks and 8 years after the start of administration in the group administered EHDP (EHDP group) were 15\%, 25\%, and 30\%, respectively, while the corresponding values in the non-administration (control) group were 30\%, 40\%, and 45\%, respectively. Within 12 weeks after operation, the ectopic bone formation occurred in $33 \%$ of all patients with the ectopic bone formation and $17 \%$ of the patients administered EHDP. According to the Finermann's classification, grade 1 was observed in 67\%, grade 2 in $22 \%$, and grade 3 in $11 \%$ of all patients with the ectopic bone formation 24 weeks postoperatively, while grade 1 was observed in $73 \%$ and grade 2 in $13 \%$ grade 3 in $14 \% 8$ years postoperatively.

Conclusion The incidence of ectopic bone formation has been reported to range from $15 \%$ to $90 \%$ in Western countries. In contrast, the incidence in Japan is $15.7-38.5 \%$, being lower than in Western countries. The severity has also been reported to be mild in Japan, as compared to cases in Western countries. In our data, the incidences were $20 \%$ and $30 \%$ in the control and EHDP groups, respectively, 24 weeks postoperatively, and the mildest grade 1 accounted for $67 \%$. The ectopic bone formation manifested within 12 weeks after operation in $13 \%$ of the patients who had the condition, showing that the occurrence was suppressed during this period. These results suggest that the administration is efficacious for postoperatively early prevention of ectopic bone formation and that the indications for the administration must be taken into much consideration.

\section{SAT0057 A DOUBLE-BLIND, PLACEBO-CONTROLLED STUDY TO EVALUATE THE EFFECTS OF VALDECOXIB, A NOVEL COX-2 SPECIFIC INHIBITOR, ON PLATELET FUNCTION IN THE ELDERLY}

${ }^{1} \mathrm{PT}$ Leese, ${ }^{2} \mathrm{D}$ Recker, ${ }^{2} \mathrm{ME}$ Kuss. ${ }^{1}$ Medical Scientific Services, Quintiles Phase / Services, Lenexa; ${ }^{2}$ Research and Development, Pharmacia Corporation, Skokie, USA

\subsection{6/annrheumdis-2001.432}

Background Valdecoxib is a novel oral COX-2 specific inhibitor. COX-2 specific inhibitors effectively treat pain and inflammation without causing many of the side effects commonly associated with conventional NSAIDs.

Objectives The purpose of this study was to compare the effects of valdecoxib to ibuprofen on platelet function in healthy subjects, $>=65$ years of age.

Methods In this single-centre, double-blind, placebo-controlled, parallel-group study, 65 healthy adults, aged 65-95 years, were randomised to receive valdecoxib $40 \mathrm{mg}$ BID, ibuprofen $800 \mathrm{mg}$ TID, or placebo for 7.5 days. Platelet aggregation in response to arachidonate (AA), adenosine diphosphate (ADP), or collagen; serum thromboxane $\mathrm{B}_{2}\left(\mathrm{TxB}_{2}\right)$ concentrations; and Simplate II bleeding times were assessed at 2, 4, and $8 \mathrm{~h}$ after dosing on Days 1 and 8 . Vital signs and adverse events were monitored throughout the study.
Results Platelet aggregation responses to AA, collagen, and ADP were not affected by treatment with valdecoxib $40 \mathrm{mg}$ BID. In contrast, ibuprofen resulted in marked decreases in AA-induced platelet aggregation at the $2 \mathrm{~h}$ and $4 \mathrm{~h}$ assessments on Days 1 and 8 . The effects of ibuprofen on platelet aggregation in response to collagen and ADP were not as great as seen with AA. However, for all three stimuli, ibuprofen demonstrated significantly greater decreases in platelet aggregation compared to placebo and valdecoxib at several time points. Valdecoxib $40 \mathrm{mg}$ BID had no effect on bleeding times or serum $\mathrm{TxB}_{2}$ concentrations compared to placebo. Bleeding times were significantly prolonged $(\mathrm{p}<=0.013)$ and serum $\mathrm{TxB}_{2}$ concentrations significantly reduced $(\mathrm{p}<=0.026)$ in ibuprofen-treated subjects.

\begin{tabular}{llll}
\multicolumn{1}{l}{ Abstract SAT0057 Table 1} & & \\
\hline & Placebo & $\begin{array}{l}\text { Valdecoxib } \\
\mathbf{4 0 ~} \mathbf{~ m g ~ B I D ~}\end{array}$ & $\begin{array}{l}\text { Ibuprofen } \\
\mathbf{8 0 0} \mathbf{~ m g ~ T I D ~}\end{array}$ \\
\hline Med. change $30 \mathrm{~min}$ & -3.0 & -2.0 & -1.0 \\
Med. change 2 h & -2.0 & $1.0^{*}$ & $-70.0^{* *}$ \\
Med. change 4 h & -1.0 & $0.0^{*}$ & $-60.0^{* *}$ \\
Med. change 8 h & -2.0 & -2.0 & -1.0 \\
\hline
\end{tabular}

Platelet Aggregation Response to Arachidonate (\%), Median Change From Baseline After Final Dose on Day 8 ( ${ }^{*} \mathrm{p}<=0.05$ vs ibuprofen, ${ }^{* *} \mathrm{p}<=0.05$ vs placebo).

Conclusion Valdecoxib $40 \mathrm{mg}$ BID does not affect platelet function, serum $\mathrm{TxB}_{2}$ levels or bleeding times, and is well tolerated in healthy elderly subjects. However, ibuprofen significantly alters hemostasis. These findings suggest that valdecoxib can provide its previously demonstrated analgesic and anti-inflammatory therapeutic benefits without negatively influencing platelet function in subjects $>=65$ years.

Sponsored by Pharmacia Corporation and Pfizer, Inc.

\section{SAT0058 THE NOVEL COX-2 SPECIFIC INHIBITOR, VALDECOXIB, DOES NOT AFFECT PLATELET FUNCTION IN HEALTHY ADULTS}

${ }^{1} \mathrm{PT}$ Leese, ${ }^{2} \mathrm{D}$ Recker, ${ }^{2} \mathrm{ME}$ Kuss. ${ }^{1}$ Medical Scientific Services, Quintiles Phase I Services, Lenexa; ${ }^{2}$ Research and Development, Pharmacia Corporation, Skokie, USA

10.1136/annrheumdis-2001.433

Background Conventional NSAIDs have traditionally been used to manage pain and inflammation; however, as nonspecific inhibitors of cyclooxygenase (COX-1 and COX-2), they are associated with significant adverse events, including impaired platelet function.

Objectives The purpose of this study was to compare the effect of valdecoxib, a new COX-2 specific inhibitor, on platelet aggregation and bleeding time to that of the conventional NSAIDs, naproxen and diclofenac.

Methods This was a single-centre, double-blind, randomised comparison of valdecoxib $40 \mathrm{mg}$ BID, naproxen $500 \mathrm{mg}$ BID, diclofenac $75 \mathrm{mg}$ BID, and placebo in healthy adult subjects. Sixty-two subjects received active medication or placebo for 7.5 days. Platelet aggregation responses to arachidonate (AA), collagen, and adenosine diphosphate (ADP); Simplate II bleeding times; and serum thromboxane $(\mathrm{Tx}) \mathrm{B}_{2}$ concentrations were measured at baseline; 30 min predose, 2,4 , and $8 \mathrm{~h}$ postdose on Day 1; and 2, 4, and $8 \mathrm{~h}$ after the final dose on Day 8 . 
Results Valdecoxib produced no observable effects on Days 1 and 8 on platelet aggregation responses to AA, collagen, or ADP. Compared to placebo, valdecoxib produced no significant differences at any assessment. In contrast, naproxen significantly reduced all three platelet aggregation responses compared to placebo at most assessment times. The diclofenac group experienced significant reductions in AA-induced platelet aggregation compared to placebo at most assessment times, with fewer significant changes observed in response to collagen and ADP. Valdecoxib also had no effect on bleeding time compared to placebo $(\mathrm{p}>=0.136)$. Serum $\mathrm{TxB}_{2}$ was not significantly altered from baseline for either valdecoxib or placebo at any assessment time ( $\mathrm{p}>=0.267$ ), while significant differences from baseline were seen for naproxen at all assessment times when compared to placebo $(\mathrm{p}<=0.002)$.

\begin{tabular}{|c|c|c|c|c|}
\hline & Placebo & $\begin{array}{l}\text { Valdecoxib } \\
40 \mathrm{mg} \text { BID }\end{array}$ & $\begin{array}{l}\text { Naproxen } \\
500 \mathrm{mg} \text { BID }\end{array}$ & $\begin{array}{l}\text { Diclofenac } \\
75 \mathrm{mg} \text { BID }\end{array}$ \\
\hline Med. change $-30 \mathrm{~min}$ & 3.0 & 4.0 & $-80.0^{* * *}$ & -3.5 \\
\hline Med. change $2 \mathrm{~h}$ & 3.0 & 3.0 & $-81.0^{* * *}$ & $-8.5^{* *}$ \\
\hline Med. change $4 \mathrm{~h}$ & 0.0 & 3.0 & $-79.0^{* * *}$ & $-41.0^{*}$ \\
\hline Med change $8 \mathrm{~h}$ & 2.0 & 2.0 & $-80.0^{* * *}$ & $-11.0^{* *}$ \\
\hline
\end{tabular}

Platelet Aggregation Response to Arachidonate (\%), Median Change From Baseline After the Final Dose on Day $8\left({ }^{*} p<0.05\right.$ vs placebo, ${ }^{* *} p<0.01$ vs placebo, ${ }^{* * *} p<0.001$ vs placebo).

Conclusion The lack of effect on platelet aggregation and bleeding time would suggest that valdecoxib will have an improved clinical safety profile over conventional NSAIDs, particularly in patients for whom bleeding complications are a concern.

Sponsored by Pharmacia Corporation and Pfizer, Inc.

\section{SAT0059 GREATER EFFICACY FOR DICLOFENAC/MISOPROSTOL (ARTHROTEC) COMPARED TO ACETAMINOPHEN IN A RANDOMISED, DOUBLE-BLIND, MULTICENTER, CROSSOVER CLINICAL TRIAL IN PATIENTS WITH OSTEOARTHRITIS OF THE HIP OR KNEE IS MOST EVIDENT IN PATIENTS WITH THE MOST SEVERE OSTEOARTHRITIS}

T Sokka, T Pincus. Division of Rheumatology, Vanderbilt University, Nashville, USA

\subsection{6/annrheumdis-2001.434}

Background Acetaminophen (paracetamol) is recommended as initial therapy for osteoarthritis of the hip or knee according to guidelines of the American College of Rheumatology (ACR) prior to use of nonsteroidal anti-inflammatory drugs (NSAIDs), athough patient surveys indicate that most patients regard NSAIDs as having greater efficacy than acetaminophen.

Objectives To compare responses of patients with osteoarthritis of the hip or knee in a randomised, controlled clinical trial of diclofenac/misoprostol (Arthrotec, ARTH) compared to acetaminophen (ACET) according to severity at baseline of scores of the Western Ontario McMaster (WOMAC) osteoarthritis scale and visual analogue scale (VAS) for pain, the two primary outcomes in the clinical trial.

Methods 227 patients with radiographic stage 2-4 osteoarthritis of the hip or knee received either 6 weeks of ARTH $75 \mathrm{mg}$ twice a day or ACET 1,000 mg four times a day after a washout period, and then the other drug for 6 weeks, in a randomised, double-blind, multicenter, cross-over clinical trial. Changes in scores for the two primary outcomes while taking ACET or ARTH were analysed accoring to tertiles at baseline for each scale.

Results Overall, WOMAC pain scores were improved by 7.8 of 100 units $(\mathrm{p}<0.001)$, and pain VAS scores were improved by 14.6 of 100 units $(\mathrm{p}<0.001)$, while taking ARTH verus ACET. Differences between changes in WOMAC scores while taking ARTH versus ACET were 3.1 for patients in the lowest tertile at baseline $(\mathrm{p}=0.30)$, compared to 9.5 for the middle tertile $(\mathrm{p}<$ 0.001 ), and 12.2 for those in the highest baseline tertile ( $\mathrm{p}<$ 0.001). Differences between changes in pain VAS scores while taking ARTH versus ACET were 4.9 for patients in the lowest tertile at baseline $(p=0.25)$, compared to 16.6 for the middle tertile $(p<0.001)$, and 21.0 for those in the highest baseline tertile $(\mathrm{p}<0.001)$.

Conclusion Patients with mild osteoarthritis of the hip or knee have similar responses to ARTH and ACET, possibly because patients in the lowest tertile have the least capacity for improvement. Patients with more severe osteoarhtritis appear much more likely to benefit from ARTH.

\section{SAT0060 OSTEOARTHRITIS (OA) OF THE HIP: TOLERANCE AND EFFICACY OF INTRA-ARTICULAR HYALURONIC ACID (HA)}

O Brocq, V Breuil, G Tran, C Grisot, P Flory, L Euller-Ziegler. Rheumatology Department, University Hospital Archet 1, Nice, France

\subsection{6/annrheumdis-2001.435}

\section{Background}

Objectives Intra-articular injection of $\mathrm{HA}$, a visco-supplement, can be an interesting option to treat OA; it has been mostly studied for OA of the knee. We studied the short-term tolerance and efficacy of an intra-articular injection of Hylane G-F 20 (Synvisc) in hip OA.

Methods We performed an open prospective study in patients with OA of the hip (radiological and/or CT scan criteria: Kellgren radiological score $40 \mathrm{~mm}$ and/or Lequesne score $>6$ ), without surgery schedule for one year and without any pathology which may contribute to the pain. For each patient, articular amplitudes, VAS and Lequesne score were recorded at day $0,30,60,90,120$. The injection of one vial of the drug was realised after radiological verification of the position of the needle by injecting $1 / 2 \mathrm{cc}$ of a iodic contrast fluid. After

Results 30 injections were performed in 22 patients $(13 \mathrm{~F}+9$ $\mathrm{M})$, mean aged 54.7 years (37-83). The Kellgren score was: stade 1(2); st 2(11); st 3(9). Two patients with iode allergy were pre-treated by hydroxyzine. The patients received analgesics (all); NSAID (11); MOA (15).

\begin{tabular}{|c|c|c|c|c|c|}
\hline & Day 0 & Day 30 & Day 60 & Day 90 & Day 120 \\
\hline $\begin{array}{l}\mathrm{N}^{\circ} \text { of patients } \\
\text { VAS }(\mathrm{mm})\end{array}$ & 22 & 22 & & & \\
\hline
\end{tabular}

Conclusion Hylane G-F20 injection in the hip joint appeared to be well tolerated. It may have a special interest in patients $<60$ years old suffering from hip OA, notably for delaying surgery. 